\title{
Variability in Vitamin A Intake of Pregnant Women in Ngaoundere-Cameroon with Geographic Origin, Socio-Professional and Demographic Factors
}

\author{
Edith N. Fombang1 ${ }^{*}$, Wilfred Damndja Ngaha ${ }^{1}$, Richard Aba Ejoh ${ }^{1,2}$ \\ ${ }^{1}$ Department of Food Science and Nutrition, National School of Agro-Industrial Sciences, \\ University of Ngaoundere, Ngaoundéré, Cameroon \\ ${ }^{2}$ College of Technology, University of Bamenda, Bambili, Cameroon \\ Email: "edfombang@yahoo.fr
}

Received 21 December 2015; accepted 13 February 2016; published 16 February 2016

Copyright (C) 2016 by authors and Scientific Research Publishing Inc.

This work is licensed under the Creative Commons Attribution International License (CC BY). http://creativecommons.org/licenses/by/4.0/

c) (i) Open Access

\begin{abstract}
Variability in vitamin A (VA) intake of pregnant women in Ngaoundere town according to geographic origin, socio-professional and demographic factors was studied. A total of 100 pregnant women attending ante natal visits at the Regional Hospital in Ngaoundere were involved in the survey. A questionnaire was used to obtain information on geographic origin, socio-professional status, birth history, demographic and anthropometric factors. Dietary intake was assessed using 24-hour dietary recall. Meals potentially rich in VA consumed by these women were collected, their carotenoids contents quantified and VA activity determined by conversion. Results indicated that daily VA intake of these women varied significantly $(p<0.05)$ with geographic origin, level of education and age of pregnancy. VA intake of pregnant women of Northern origin (Adamawa, North and Far North Regions) was significantly $(p<0.05)$ lower $(496 \mu \mathrm{g} / \mathrm{day} /$ woman $)$ than that of women of Southern origin $(588 \mu \mathrm{g} /$ day/woman), although both were below the recommended intake of $800 \mu \mathrm{g} / \mathrm{day} /$ woman. The more educated a woman and the older her pregnancy, the higher her VA intake. VA consumption of pregnant women of Northern origin was significantly influenced by their age, whereas for pregnant women of Southern origin, BMI (Body Mass Index) equally had a significant influence on their VA intake. Socio-professional status, marital status and number of children did not significantly influence the daily VA intake of these women. Thus, a pregnant woman originating from the Northern part of the country and having no formal education, consumed less foods rich in carotenoids and therefore was more at risk for vitamin A deficiency.
\end{abstract}

${ }^{*}$ Corresponding author.

How to cite this paper: Fombang, E.N., Ngaha, W.D. and Ejoh, R.A. (2016) Variability in Vitamin A Intake of Pregnant Women in Ngaoundere-Cameroon with Geographic Origin, Socio-Professional and Demographic Factors. Food and Nutrition Sciences, 7, 74-82. http://dx.doi.org/10.4236/fns.2016.72009 


\section{Keywords}

\section{Pregnant Women, Geographic Origin, Socio-Demographic Factors, Ngaoundere, Vitamin A Intake}

\section{Introduction}

Vitamin A is an important nutrient in the body and participates in a number of biological roles including vision, growth and reproduction [1]. Good vitamin A status is important for the body to carry out these functions. The dietary needs for vitamin A are normally provided for as preformed retinol and provitamin A carotenoids [1]. In vitamin A deficiency (VAD) therefore, functional disorders are observed. Deficiency in vitamin A during infancy, pregnancy and lactation, has been recognized as a public health problem, contributing significantly to a high rate of maternal and infant mortality [2]. VAD usually results from an inadequate intake amongst other factors. The joint FAO/WHO expert consultation on human vitamin and mineral requirements recommends a daily intake of $800 \mu \mathrm{g}$ Retinol Equivalence (RE) for pregnant women 19 years and above [1].

In Cameroon, $18 \%$ of pregnant women suffer from VAD, and the situation is even more critical in preschool children (39\%) [3]. Recent studies in the town of Ngaoundere, in the Adamawa Region of Cameroon reveal that $37.5 \%$ of pregnant women are exposed to acute VAD, with $20 \%$ of them at risk for severe VAD [4]. This calls for concern as VAD in the mother can result in malformations in the fetus and predispose the child to VAD [2]. Poor dietary patterns before and during pregnancy have been identified as one of the major causes of malnutrition in women and children [5], and VA content of human breast milk is strongly affected by maternal nutrition during pregnancy and lactation [6].

There have been reports showing that food consumption as well as the quantity and quality of the diet composition are influenced by social factors [7]-[8]. Higher socio-economic levels have been associated with healthier dietary patterns whereas poor socio-economic status is linked to poor dietary patterns. In a study conducted in China, it was observed that feeding practices were strongly correlated with malnutrition and anemia in children 0 - 18 months old [9]. Nutritional status therefore, is influenced by our food habits, which in turn are influenced by factors such as cost, income, availability, culture, education, skills (e.g. cooking), beliefs and knowledge about foods [10]-[12]. In an attempt to understand this relationship with regards to vitamin A status, this study sets out to determine the differences in vitamin A intake of pregnant women in Ngaoundere with respect to their geographic origin, socio-professional, anthropometric and demographic factors.

\section{Material and Methods}

\subsection{Framework of the Study}

The study was conducted in the town of Ngaoundere, in the Adamawa Region of Cameroon, whose characteristics have previously been described by Ngaha et al. [4].

\subsection{Sampling of Subjects}

Pregnant women attending pre natal visits at the Ngaoundere Regional Hospital (NHR) and who gave their consent to participate in the study, constituted the study population. These women were from Ngaoundere town and of varying socioeconomic and cultural background. The recruitment stage lasted for two weeks, from the $17^{\text {th }}$ to $31^{\text {st }}$ March 2012, and the study period itself lasted for one month at their residence. From this population, pregnant women aged 18 to 40 years old, not suffering from any infectious disease, not undergoing any treatment, not on any diet, who did not use contraceptive pills prior to pregnancy and who gave their consent to be admitted in the study were recruited. Those who did not respond to these criteria were excluded from the study. One hundred women effectively took part in the study.

\subsection{Data Collection}

Demographic, anthropometric and socio-economic data of the women was collected through interviews, using structured questionnaires to obtain information on variables such as sex, age, weight, height, level of education, 
marital status, geographic origin, age of pregnancy, number of births and professional status. Body Mass Index (BMI) was calculated from weight and height measurements using the Quetelet index: $\mathrm{BMI}=\mathrm{W} / \mathrm{H}^{2}(\mathrm{~W}$, is weight in $\mathrm{Kg}$ and $\mathrm{H}$, is Height in $\mathrm{m})$.

The women were separated into two groups based on their geographic origin; women from the North, that includes the three Northern Regions of Cameroon (Adamawa, North and Far North), and women from the South, representing the seven Southern Regions of Cameroon (Center, North-West, South-West, Littoral, South, East and West). This separation was based on the fact that the culture and food habits of the North are different from those of the South.

Food and nutrients intake was assessed using 24 hour dietary recall as described previously [4]. Meal samples were collected and carotenoid content determined [4]. VA activity was calculated from this, based on the assumption that $12 \mu \mathrm{g}$ of dietary carotenoid yields $1 \mu \mathrm{g}$ of vitamin A activity or $1 \mu \mathrm{g}$ of dietary carotenoids equals $0.083 \mu \mathrm{g}$ RE [13]. Vitamin A from animal products was obtained from Food Composition Tables [14]. Total vitamin A intake of pregnant women was thus the sum of intakes from vegetable and animal portions of various dishes consumed during the study period. Thus, the daily vitamin A intake was the mean consumption per woman per day during the study period, and the general intake for each group of women was the mean consumption for all the women in that group.

\subsection{Statistical Analysis}

The data obtained in this study was subjected to analysis of variance (ANOVA) using the statistical software Statgraphics centurion XVI.0. Mean and standard deviation were calculated using Microsoft Excel 2010. Where appropriate, percentages (\%) were used.

\section{Results}

\subsection{Socio-Professional and Demographic Characteristics of the Studied Population}

Table 1 shows the distribution of the studied population with respect to measured characteristics. Majority of the women (76) originated from the Northern part of the country (Adamawa, North and Far North Regions) whereas 24 came from the Southern Regions. However, irrespective of geographic origin, over 90\% of the women (93\% of Northern origin and 92\% of Southern origin) were under 30 years of age. Teenage mothers with ages ranging between 14 and 20 years represented $42 \%$ and 38\% of mothers of Northern and Southern origin respectively. However, more of the women of Northern origin (96\%) were married compared to women of Southern origin (58\%). Education wise, we observed a high level of illiteracy among the Northern women where $49 \%$ had never been to school compared to $0 \%$ for Southern women. Those who made it to school barely had primary education, with a meager $9 \%$ and $4 \%$ having secondary and university education respectively. Women of Southern origin on the contrary are highly educated with $58 \%$ having secondary education and $25 \%$ having attended University. Half of the women of Southern origin were workers, which means they had a stable job compared to only $22 \%$ of the women of the Northern origin, who were predominantly housewives (69\%) with no income generating activity. Students made up more than a quarter of the women of Southern origin. Comparatively, majority of the women of Northern origin (95\%) already had two, three or more children, whereas amongst those of Southern origin 38\% were in their first pregnancy and 56\% had one or two children. Concerning their current pregnancy, majority of the women of Northern origin (57\%) were in the first trimester of pregnancy whereas for the women of Southern origin (54\%) were in the second trimester. Irrespective of geographic origin, over $80 \%$ of the women in each group had a BMI in the normal range.

\subsection{Food and Nutrients Intake of Studied Population}

The daily vitamin A intake per woman with respect to their geographic origin is presented in Table 2 . With an average intake of $496 \mu \mathrm{g} / \mathrm{day} /$ woman for pregnant women from the Northern part of the country, they consume significantly $(p<0.05)$ less vitamin A than women of Southern origin (588 $\mu \mathrm{g} / \mathrm{day} / \mathrm{woman})$. Regardless of the socio-professional, demographic and anthropometric characteristics, the vitamin A intake of women of Southern origin was generally significantly higher than that of women of Northern origin (Table 2). VA intake of pregnant women was significantly $(p<0.05)$ influenced by level of education and age of pregnancy irrespective of geographic origin. The higher the level of education and the older the pregnancy, the higher the consumption of 
Table 1. Socio-professional and demographic characteristics of the studied population according to geographic origin.

\begin{tabular}{|c|c|c|c|c|}
\hline \multirow{2}{*}{ Parameters } & \multirow{2}{*}{ Range } & \multicolumn{2}{|c|}{ Number of women n (percentage) } & \multirow{2}{*}{ Total } \\
\hline & & Northern & Southern & \\
\hline \multirow{4}{*}{ Age distribution } & $14-20$ & $32(42)$ & $09(38)$ & 41 \\
\hline & {$[21-30]$} & $39(51)$ & $13(54)$ & 52 \\
\hline & $>30$ & $05(7)$ & $02(8)$ & 07 \\
\hline & Total & $76(100)$ & $24(100)$ & 100 \\
\hline \multirow{5}{*}{ Level of education } & None & $37(49)$ & $00(0)$ & 37 \\
\hline & Primary education & $29(38)$ & $04(17)$ & 33 \\
\hline & Secondary education & $07(9)$ & $14(58)$ & 21 \\
\hline & University education & $03(4)$ & $06(25)$ & 09 \\
\hline & Total & $76(100)$ & $24(100)$ & 100 \\
\hline \multirow{4}{*}{ Socio-professional status } & Housewife & $52(69)$ & $05(21)$ & 57 \\
\hline & Worker & $17(22)$ & $12(50)$ & 29 \\
\hline & Student & $07(9)$ & $07(29)$ & 14 \\
\hline & Total & $76(100)$ & $24(100)$ & 100 \\
\hline \multirow{3}{*}{ Marital status } & Married & $73(96)$ & $14(58)$ & 87 \\
\hline & Single & $03(4)$ & $10(42)$ & 13 \\
\hline & Total & $76(100)$ & $24(100)$ & 100 \\
\hline \multirow{5}{*}{ Number of children } & 0 & $01(1)$ & $09(38)$ & 10 \\
\hline & 1 & $03(4)$ & $08(33)$ & 11 \\
\hline & 2 & $34(45)$ & $05(21)$ & 39 \\
\hline & $\geq 3$ & $38(50)$ & $02(8)$ & 40 \\
\hline & Total & $76(100)$ & $24(100)$ & 100 \\
\hline \multirow{4}{*}{ Age of the pregnancy } & $1^{\text {st }}$ trimester & $43(57)$ & $06(25)$ & 49 \\
\hline & $2^{\text {nd }}$ trimester & $13(17)$ & $13(54)$ & 26 \\
\hline & $3^{\text {rd }}$ trimester & $20(26)$ & $05(21)$ & 25 \\
\hline & Total & $76(100)$ & $24(100)$ & 100 \\
\hline \multirow{4}{*}{ BMI } & $<18.5$ & $08(11)$ & $01(4)$ & 09 \\
\hline & {$[18.5,24.9]$} & $64(84)$ & $20(83)$ & 84 \\
\hline & {$[25,29.9]$} & $04(5)$ & $03(13)$ & 07 \\
\hline & Total & $76(100)$ & $24(100)$ & 100 \\
\hline
\end{tabular}

vitamin A rich foods. Women with normal and higher BMI consumed more vitamin A than underweight women. This was however, only significant $(\mathrm{p}<0.05)$ for women of Southern origin but not for those of Northern origin. In both study groups, women over 30 years of age consumed less vitamin A than younger women. However, when the studied population is considered in general, that is the Northern and Southern women together, it is only the level of education that significantly $(\mathrm{p}<0.05)$ influenced the daily vitamin A intake of the women, with the intake of women having no education being significantly $(p<0.05)$ lower than that of women who have been to school. Socio-professional status, marital status, number of children, BMI and age of the women had no significant influence ( $p>0.05$ ) on daily vitamin A intake of these pregnant women.

Table 3 shows the dishes potentially rich in vitamin A consumed by the pregnant women during the study. It arises from this table that in the course of the one month study period, pregnant women from Northern Cameroon consumed predominantly three dishes with high VA potential, prepared using Adansonia digitata (Baobab 
Table 2. Vitamin A intake according to geographic origin, socio-professional and demographic parameters* .

\begin{tabular}{|c|c|c|c|c|}
\hline \multirow{2}{*}{ Parameter } & \multirow{2}{*}{ Range } & \multicolumn{3}{|c|}{ Daily vitamin A intake ( $\mu$ g/day) } \\
\hline & & Northern & Southern & General \\
\hline \multirow{3}{*}{ Age distribution } & $14-20$ & $497 \pm 12^{\mathrm{bcd} 1}$ & $593 \pm 11^{\text {efgh } 2}$ & $545 \pm 54^{\text {abc }}$ \\
\hline & {$[21-30]$} & $501 \pm 17^{\mathrm{cd} 1}$ & $593 \pm 15^{\text {efgh } 2}$ & $547 \pm 52^{\mathrm{abc}}$ \\
\hline & $>30$ & $476 \pm 03^{\mathrm{ab} 1}$ & $572 \pm 06^{\text {abcde2 }}$ & $524 \pm 53^{\mathrm{ab}}$ \\
\hline \multirow{4}{*}{ Level of education } & None & $468 \pm 12^{\mathrm{a} 1}$ & $/ /$ & $468 \pm 12^{\mathrm{a}}$ \\
\hline & Primary education & $489 \pm 07^{\mathrm{abcd} 1}$ & $585 \pm 09^{\text {cdefg } 2}$ & $537 \pm 53^{\text {abc }}$ \\
\hline & Secondary education & $495 \pm 15^{\mathrm{bcd} 1}$ & $591 \pm 13^{\text {efgh2 }}$ & $543 \pm 54^{\mathrm{abc}}$ \\
\hline & University education & $606 \pm 04^{\mathrm{f} 1}$ & $610 \pm 10^{\mathrm{h1}}$ & $608 \pm 7^{c}$ \\
\hline \multirow{3}{*}{ Socio-professional status } & Housewife & $489 \pm 20^{\mathrm{abcd} 1}$ & $561 \pm 14^{\mathrm{abc} 2}$ & $525 \pm 42^{\mathrm{ab}}$ \\
\hline & Worker & $512 \pm 11^{\mathrm{d} 1}$ & $584 \pm 08^{\text {cdefg } 2}$ & $548 \pm 40^{\mathrm{abc}}$ \\
\hline & Student & $510 \pm 13^{\mathrm{d} 1}$ & $580 \pm 12^{\text {abcdef2 }}$ & $545 \pm 40^{\mathrm{abc}}$ \\
\hline \multirow{2}{*}{ Marital status } & Married & $481 \pm 19^{\mathrm{abc} 1}$ & $583 \pm 23^{\text {bcdefg2 }}$ & $532 \pm 59^{\mathrm{abc}}$ \\
\hline & Single & $497 \pm 17^{\mathrm{bcd} 1}$ & $595 \pm 15^{\mathrm{efgh} 2}$ & $546 \pm 56^{\mathrm{abc}}$ \\
\hline \multirow{4}{*}{ Number of children } & 0 & $491 \pm 00^{\mathrm{abcd} 1}$ & $585 \pm 11^{\text {cdefg2 }}$ & $538 \pm 52^{\mathrm{abc}}$ \\
\hline & 1 & $495 \pm 07^{\mathrm{bcd} 1}$ & $593 \pm 14^{\mathrm{efgh} 2}$ & $544 \pm 55^{\text {abc }}$ \\
\hline & 2 & $492 \pm 15^{\mathrm{bcd} 1}$ & $590 \pm 13^{\mathrm{efgh} 2}$ & $541 \pm 55^{\text {abc }}$ \\
\hline & $\geq 3$ & $480 \pm 13^{\mathrm{abc} 1}$ & $588 \pm 11^{\operatorname{defgh} 2}$ & $534 \pm 60^{\text {abc }}$ \\
\hline \multirow{3}{*}{ Age of the pregnancy } & $1^{\text {st }}$ trimester & $484 \pm 14^{\mathrm{abc} 1}$ & $556 \pm 26^{\mathrm{a} 2}$ & $520 \pm 44^{\mathrm{ab}}$ \\
\hline & $2^{\text {nd }}$ trimester & $493 \pm 20^{\mathrm{bcd} 1}$ & $559 \pm 23^{\mathrm{ab} 2}$ & $526 \pm 41^{\mathrm{abc}}$ \\
\hline & $3^{\text {rd }}$ trimester & $536 \pm 12^{\mathrm{e} 1}$ & $606 \pm 18^{\text {gh2 }}$ & $571 \pm 41^{\mathrm{bc}}$ \\
\hline \multirow{3}{*}{ BMI } & $<18.5$ & $475 \pm 10^{\mathrm{ab} 1}$ & $565 \pm 00^{\mathrm{abcd} 2}$ & $520 \pm 50^{\mathrm{ab}}$ \\
\hline & [18.5 - 24.9] & $494 \pm 21^{\mathrm{bcd} 1}$ & $600 \pm 17^{\mathrm{fgh} 2}$ & $547 \pm 61^{\text {abc }}$ \\
\hline & [25 - 29.9] & $498 \pm 13^{\mathrm{bcd} 1}$ & $602 \pm 14^{\mathrm{fgh} 2}$ & $550 \pm 58^{\mathrm{abc}}$ \\
\hline Geographic origin & Whole population & $496 \pm 23^{\mathrm{bcd} 1}$ & $588 \pm 21^{\text {defgh } 2}$ & $539 \pm 43^{\mathrm{abc}}$ \\
\hline
\end{tabular}

\footnotetext{
"Values followed by the same letter in a column indicates no significant difference $(\mathrm{p}>0.05)$ in VA intake; ${ }^{*}$ Values followed by different figures in a
} row indicates a significant difference $(\mathrm{p}<0.05)$ in VA intake.

leaves), Hibiscus sabdarifa (Folere) and Corchorus olitorius (Lalo), cooked with local ingredients. In contrast, pregnant women originating from the Southern part of the country consumed up to 8 different dishes prepared from vegetables such as Gnetum africanum (Eru), Solanum nigrum (Zom), Vernonia amygdalina (Ndole), Amaranthus hybridus (Folong) and Vigna unguiculata (Koki) with variations in the methods of preparation, some with red palm oil and others with carrots and tomatoes (Table 3). It is evident from this table that majority of dishes consumed by Southern pregnant women are richer in vitamin A content $(3.00 \pm 0.12$ to $6.80 \pm 0.21 \mathrm{mg}$ of vitamin A) than those of the Northern women (1.59 \pm 0.07 to $3.13 \pm 0.02 \mathrm{mg}$ of vitamin A).

\section{Discussion}

With daily VA intake of $496 \pm 23 \mu \mathrm{g}$ for pregnant women from the Northern Region and $588 \pm 24 \mu \mathrm{g}$ for those of the Southern Region (Table 2), it appears that the intake of vitamin A rich foods in Cameroon is significantly $(\mathrm{p}<0.05)$ influenced by geographic origin and cultural values as opposed to food availability. These results corroborate those of a study conducted in the town of Yaounde by Tabuna and Tanoé who found that there was a relationship between the geographic origin of a household and its food behavior [7]. This difference in vitamin A intake of Northern and Southern women could principally be explained by the food habits in these two regions (Table 3). Dishes consumed by Southern women have higher vitamin A contents, as a consequence of the 
Table 3. Dishes potentially rich in VA consumed by pregnant women of Northern and Southern origin.

\begin{tabular}{|c|c|c|c|c|c|}
\hline \multicolumn{3}{|c|}{ Women from Southern-Cameroon } & \multicolumn{3}{|c|}{ Women from Northern-Cameroon } \\
\hline Dishes & Water (\%) & VA Eq (mg) & Dishes & Water (\%) & VA Eq ${ }^{*}(\mathrm{mg})$ \\
\hline Eru $^{1}$ (with palm oil) & $75.12 \pm 1.53$ & $6.80 \pm 0.26$ & $\begin{array}{c}\text { Baobab leaves }^{6} \\
\text { (with local ingredients) }\end{array}$ & $87.15 \pm 3.22$ & $3.13 \pm 0.02$ \\
\hline Fried zom $^{2}$ (with tomato) & $78.72 \pm 2.44$ & $5.28 \pm 0.09$ & Folere $^{7}$ & $87.95 \pm 0.48$ & $1.59 \pm 0.07$ \\
\hline Fried ndole ${ }^{3}$ (with tomato) & $76.34 \pm 2.31$ & $4.83 \pm 0.24$ & Lalo $^{8}$ & $83.04 \pm 2.41$ & $1.77 \pm 0.13$ \\
\hline Fried folong ${ }^{4}$ (with tomato) & $78.56 \pm 3.09$ & $4.62 \pm 0.13$ & & & \\
\hline Zom $^{2}$ (with groundnuts) & $81.72 \pm 2.05$ & $3.42 \pm 0.17$ & & & \\
\hline Koki $^{5}$ (with palm oil) & $64.28 \pm 3.67$ & $3.00 \pm 0.12$ & & & \\
\hline Ndole $^{3}$ (with groundnuts) & $79.35 \pm 1.79$ & $2.91 \pm 0.26$ & & & \\
\hline Folong $^{4}$ (with groundnuts) & $81.53 \pm 3.16$ & $2.77 \pm 0.33$ & & & \\
\hline
\end{tabular}

${ }^{1}$ Gnetum africanum, ${ }^{2}$ Solanum nigrum, ${ }^{3}$ Vernonia amygdalina, ${ }^{4}$ Amaranthus hybridus. ${ }^{5}$ Vigna unguiculata, ${ }^{6}$ Adansonia digitata, ${ }^{7}$ Hibiscus sabdarifa, ${ }^{8}$ Corchorus olitorius; *Vitamin A Equivalent for $100 \mathrm{~g}$ (Dry weight basis).

types of vegetables consumed and culinary practices. Vitamin A activity varies with the type of green leafy vegetable as reported by Djuikwo et al. [15]. Thus, S. nigrum, G. bucholzianum and V. amygdalina mostly consumed by pregnant women from Southern Regions are richer in provitamin A than A. digitata and $\mathrm{H}$. sabdarifa [15] mostly consumed by women of Northern Regions. In addition, women originating from the Southern Regions have the culture of using red palm oil, carrots and tomatoes in their cooking, which are rich sources of $\beta$-carotene and other carotenoids [16], contrary to the women originating from Northern Cameroon who do not have this culture. Southern women use red palm oil for the preparation of dishes like Eru, koki and zom. Furthermore, survey results reveal that women from Northern Regions preferably use smoked fish in their dishes, while women from the Southern Region consume more beef and chicken which contain respectively 25 and 85 $\mu \mathrm{g}$ VA/100 g as opposed to smoked fish which has negligible vitamin A activity [14]. All of these factors contribute to explain the higher vitamin A intake of women of Southern origin compared to those of Northern origin.

VA intake though generally lower in women aged 30 years and above, was only significant in the case of Northern women with intakes of $476 \pm 03 \mu \mathrm{g}$ /day for women aged 30 years and above, compared to $501 \pm 17$ $\mu \mathrm{g} /$ day for those aged 21 to 29 years. The significant decrease in vitamin A intake of Northern pregnant women 30 years and more $(476 \pm 03 \mu \mathrm{g})$ could be due to the fact that they are mostly in large families with three or more children, which could imply reduced food intake for the mother and the children. Generally, however the variation in food intake with age was not significant, and could be related to the fact that culinary practices are transmitted from one generation to another, from mothers to their daughters, with sometimes light modifications related to the socio-economic and environmental context. This observation is in agreement with that of MOST, USAID Micronutrient Program [17] working on the prevalence of VAD among pregnant women (14 - 43 years) from four districts of Madagascar who reported that there was no statistically significant difference among the various age brackets with respect to VAD.

On the contrary, the general daily vitamin A intake increased significantly $(\mathrm{p}<0.05)$ from $468 \pm 12 \mu \mathrm{g}$ for women who had never gone to school to $608 \pm 53 \mu \mathrm{g}$ for those who reached University. Thus, the more educated a woman is, the better her vitamin A intake irrespective of origin, although the quantities consumed are higher for women from Southern Regions compared to those from Northern Regions. The level of education is thus an important factor to take into consideration when elaborating food policies and education programs. Certainly because of their illiteracy, women with low educational level can neither read nor write, and for some cannot even express themselves in French or English, official languages in Cameroon; they thus do not grasp the messages in the multiple nutritional public awareness campaigns on radio, television, and even in the hospitals and health centers where they go for their prenatal consultations. Added to this, is the fact that they probably do not understand the importance of Nutrition not only during pregnancy, but in their life in general and that of their unborn child. In fact, it has been shown that women who receive even minimal education are generally more aware, than those who have no education, of how to utilize available resources for the improvement of 
their own nutritional status and that of their families [18]. Education can enable women make correct decisions about food choices, and to have greater access to household resources that are important to nutritional status [19]. A comparative study on maternal malnutrition in ten Sub-Saharan African countries [20] and a study in the Southern Nations, Nationalities and Peoples Region (SNNPR) of Ethiopia [21] showed that the higher the level of education, the lower the proportion of undernourished women in these communities.

These results are different from those of the WHO/FAO study [1], which found that there was no significant difference in vitamin A intake between women married or single, and whatever their level of education [1]. This could be due to the fact that in a WHO study, there were only women from secondary school and University, compared to this study where approximately $50 \%$ of the pregnant women from Northern Region had never gone to school. These results are also different from those found by Tabuna and Tanoe [7] who studied the influence of the level of education on the food behavior of the households in Yaounde town and arrived at the conclusion that there was no relationship between the two. This difference could be due to the difference in the study site given that Tabuna and Tanoe worked in Yaounde, a town located in the Southern part of Cameroon. Statistics of the population in our study showed that pregnant women from Southern Regions were more educated $(100 \%$ attended at least primary school) than those of Northern origin and this is a reflection of the level of education in these two regions [3].

The socio-professional status of the women had no significant ( $p>0.05$ ) influence on their vitamin A intake, irrespective of origin. This could be explained by the fact that culinary practices were similar among each group of women, and according to the 24 hour dietary recall, the women ate most of their meals at home. Other studies have shown no significant variation in vitamin A intake [1] or food habits in general [7] with socio-professional status. This suggests that food consumption patterns and food habits are more rooted in our cultures than in socio-professional status. Pregnant women having three or more children had lower vitamin A intake (534 $\pm 60 \mu \mathrm{g})$ compared to those having less than three children, but differences are not significant. However, the progressive decrease in vitamin A intake with number of children suggests that mothers with larger families are more at risk for VAD, possibly due to reduced food intake as they have more persons to feed. The vitamin A intake of pregnant women in Ngaoundere town is significantly $(\mathrm{p}<0.05)$ influenced by the age of pregnancy with intake increasing as we move from the first to the third trimester of pregnancy (520 to $571 \mu \mathrm{g}$ ). The increase observed in the vitamin A intake of Northern and Southern women in the third trimester of pregnancy corroborates with increased food intake at this period of increased weight gain to meet up fetal needs and to prepare for lactation [22]. The lower vitamin A intake observed in the first trimester could also be explained by the fact that at this stage of pregnancy, the amounts of cooked foods consumed may be reduced due to bouts of nausea resulting from hormonal changes in the woman's body [23].BMI is a method of assessing nutritional status of individuals, thus linked to food behaviors. Vitamin A intake being influenced by food behaviors, it thus appears important to emphasize the existence or not of a link between BMI and vitamin A intake of the studied population. Vitamin A intake increased with BMI, and the effect is more pronounced in women of Southern origin where significant $(\mathrm{p}<0.05)$ increases were observed in normal and overweight women compared to underweight women. If weight gain is linked to increase food consumption, it follows therefore that vitamin A intake will increase with increase in food consumption and weight gain.

Even though, the average daily vitamin A intake of women from the Northern Regions (496 $\mu \mathrm{g} / \mathrm{day})$ is significantly $(\mathrm{p}<0.05)$ lower than that of women from the Southern Regions (588 $\mu \mathrm{g} / \mathrm{day})$, both consumed less VA than the $800 \mu \mathrm{g}$ recommended daily. However, with an average daily vitamin A intake of $468 \mu \mathrm{g}$, which appears to be the lowest vitamin A consumption in the studied population, pregnant women originating from Northern Cameroon and having no formal education are the most at risk group. Indeed, the quantities of vitamin A found for these women were lower than the threshold critical values of $500 \mu \mathrm{g} / \mathrm{day}$ [4]. It can therefore be suggested that geographic origin and level of education of pregnant women in Ngaoundere town are important factors influencing their vitamin A status. Thus a pregnant woman originating from the Northern part of Cameroon and having no formal education is strongly predisposed to foods low in vitamin A, and consequently presents a higher risk of developing a severe VAD.

\section{Conclusion}

In conclusion, this study reveals suboptimal dietary intake of vitamin A $(<800 \mu \mathrm{g})$, insufficient to cover the needs of pregnant women in Ngaoundere town. Level of education, geographic origin, age of the woman, BMI and age of the pregnancy significantly influenced daily intake of vitamin A. A pregnant woman originating from 
the Northern part of Cameroon and who has never been to school is strongly exposed to VAD. Thus, nutritional intervention programs designed to reduce the prevalence of VAD should take into consideration these variables. In particular, improving the level of scholarisation of the girl child and culinary practices in the Northern Regions of Cameroon should be one of the priority areas of government action towards fighting VAD.

\section{Acknowledgements}

The authors will like to thank the pregnant women who participated in this study.

\section{References}

[1] World Health Organization and Food and Agriculture Organization of the United Nations (2004) Vitamin and Mineral Requirements in Human Nutrition. 2nd Edition, WHO, Geneva, 17-37.

[2] Azaïs-Braesco, V. and Pascal, G. (2000) Vitamin A in Pregnancy: Requirements and Safety Limits. American Journal of Clinical Nutrition, 71, 1325S-1333S.

[3] Institut National de la Statistique (INS) et ICF International (2012) Enquête Démographique et de Santé et à Indicateurs Multiples du Cameroun (EDS-MICS) 2011. INS et ICF International, Calverton.

[4] Ngaha, D.W., Fombang, E.N. and Ejoh, R.A. (2014) Dietary Intake of Vitamin A and Macronutrients among Pregnant Women in Ngaoundere Town, Adamawa Region, Cameroon. Food and Nutrition Sciences, 5, 2071-2080. http://dx.doi.org/10.4236/fns.2014.521219

[5] Sasuni, R.A. and Oredipe, V.A. (2002) Nutritional Status in Pregnancy and Prediction of Low Birth Weight: Evaluation of Table of Reference. Tropical Journal of Obstetrics Canynewl, 19, 63-67.

[6] Ibrahim, K., Hassan, T.J. and Jafarey, S.N. (1991) Plasma Vitamin A and Carotene in Maternal and Cord Blood. Asia and Oceania Journal of Obstetrics and Gynaecology, 17, 159-164.

http://dx.doi.org/10.1111/j.1447-0756.1991.tb00040.x

[7] Honoré Tabuna et Micheline Tanoé (2010) Facteurs explicatifs et développement de la consommation actuelle du safou (Dacryodes edulis) au Cameroun. World Agro Forestry Centre, West and Central Africa-Humid Tropic, 55 p.

[8] Abdollahi, M., Mohammadi-Nasrabadi, F., Houshiarrad, A., Ghaffarpur, M., Ghodsi, D. and Kalantari, N. (2014) Socio-Economic Differences in Dietary Intakes: The Comprehensive Study on Household Food Consumption Patterns and Nutritional Status of I.R. Iran. Nutrition and Food Sciences Research, 1, 19-26.

[9] Yang, W.F., Li, X., Li, Y., Zhang, S.P., Liu, L.M., Wang, X. and Li, W.M. (2012) Anemia, Malnutrition and Their Correlations with Socio-Demographic Characteristics and Feeding Practices among Infants Aged 0 - 18 Months in Rural Areas of Shaanxi Province in North Western China: A Cross-Sectional Study. BMC Public Health, 12, 11-27. http://dx.doi.org/10.1186/1471-2458-12-1127

[10] French, S.A., Story, M. and Jeffery, R.W. (2001) Environmental Influences on Eating and Physical Activity. Annual Revision of Public Health, 22, 309-335. http://dx.doi.org/10.1146/annurev.publhealth.22.1.309

[11] Janssen, I., Katzmarzyk, P.T., William, F., Boyce, W.F., King, M.A. and Picket, W. (2004) Overweight and Obesity in Canadian Adolescents and Their Associations with Dietary Habits and Physical Activity Patterns. Journal of Adolescents Health, 35, 360-367. http://dx.doi.org/10.1016/S1054-139X(04)00058-8

[12] La Rowe, T.L., Moeller, S.M. and Adams, A.K. (2007) Beverage Patterns, Diet Quality, and Body Mass Index of US Preschool and School-Aged Children. Journal of American Dietetic Association, 107, 1124-1133. http://dx.doi.org/10.1016/j.jada.2007.04.013

[13] National Research Council (1989) Recommended Dietary Allowances. 10th Edition, National Academy Press, Washington DC.

[14] Stadlmayr, B., Charrondiere, U.R., Enujiugha, V.N., Bayili, R.G., Fagbohoun, E.G., Samb, B., Addy, P., Barikmo, I., Ouattara, F., Oshaug, A., Akinyele, I., Annor, G.A., Bomfeh, K., Ene-Obong, H., Smith, I.F., Thiam, I. and Burlingame, B. (2012) West African Food Composition Table. The Food and Agriculture Organization of the United Nations (FAO), Rome.

[15] Djuikwo, V.N., Ejoh, R.A., Gouado, I., Mbofung, C.M. and Tanumihardjo, S.A. (2011) Determination of Major Carotenoids in Processed Tropical Leafy Vegetables Indigenous to Africa. Food and Nutrition Sciences, 2, 793-802. http://dx.doi.org/10.4236/fns.2011.28109

[16] Claire, M.D., Barrot, L. and Philippe, C. (2001) Produits végétaux riches en carotènes: Fiches descriptives et pratiques à l'usage des pays sahéliens. Organisation Mondiale de la Santé. http://apps.who.int/iris/bitstream/10665/70499/1/WHO NHD 01.6 fre.pdf?ua=1

[17] MOST, USAID Micronutrient Program (2004) Enquête sur la Carence en Vitamine A chez les Femmes et les Enfants 
et Enquête sur l’Anémie chez les Ecoliers de 6 à 14 ans. 58 p. http://pdf.usaid.gov/pdf_docs/Pnadc603.pdf

[18] Girma, W. and Genebo, T. (2002) Determinants of Nutritional Status of Women and Children in Ethiopia. ORC Macro, Calverton.

[19] Administration Committee on Coordination/Sub-Committee on Nutrition (ACC/SCN) (1990) Women and Nutrition. Symposium Report, Nutrition Policy Discussion Paper No. 6.

[20] Loaiza, E. (1997) Maternal Nutritional Status. DHS Comparative Studies No. 24, Macro International Inc., Calverton.

[21] Teller, H. and Yimar, G. (2000) Levels and Determinants of Malnutrition in Adolescent and Adult Women in Southern Ethiopia. Ethiopian Journal of Health Development, 14, 57-66.

[22] Nicola Day (2012) Bien manger pour avoir un bébé en santé. Centre de ressources en Nutrition. http://www.nutritionrc.ca

[23] Wittenberg, S. (2012) Alimentation saine pour la femme enceinte. Swissmilk, Berne 143165F. http://www.swissmilk.ch/de/shop/-dl-/fileadmin/filemount/brochures-nutritionelles-alimentation-saine-pour-la-femmeenceinte-143165-fr.pdf 